Sādhanā Vol. 37, Part 5, October 2012, pp. 587-593. (C) Indian Academy of Sciences

\title{
Comparative evaluation of tungsten inert gas and laser beam welding of AA5083-H321
}

\author{
K SUBBAIAH $^{1, *}$, M GEETHA $^{2}$, B SHANMUGARAJAN $^{3}$ \\ and S R KOTESWARA RAO ${ }^{4}$
}
${ }^{1}$ Sri Sivasubramaniya Nadar College of Engineering, Chennai 603 110, India
${ }^{2}$ VIT University, Vellore 632 014, India
${ }^{3}$ Centre for Laser Processing of Materials, International Advanced Research Centre for Powder Metallurgy and New Materials, Hyderabad 500 005, India
${ }^{4}$ Tagore Engineering College, Chennai 600 048, India
e-mail: subbaiahk@ssn.edu.in

MS received 8 November 2011; revised 25 June 2012; accepted 18 July 2012

\begin{abstract}
In this study, the bead-on-plate welds were made on AA5083-H321 alloy plates using both tungsten inert gas (TIG) welding and laser beam (LB) welding processes to study the enhancement of mechanical properties such as weld yield strength and hardness. The low heat input of laser beam welding effectively reduced the size of the fusion zone and heat affected zone compared to tungsten inert gas welding process. High speed LB welding and fast heating and cooling of LB welding process hinders grain growth compared to TIG welding process. The effect of vapourization of volatile alloying elements is also considered. It seems that magnesium evaporation is relatively less in LB welding compared to TIG welding. Tensile testing of the welded joints revealed that LB welding results in superior mechanical properties. It is concluded that LB welding process is more suitable to join AA5083-H321.
\end{abstract}

Keywords. Aluminum alloys; laser beam welding; mechanical properties; vapourization.

\section{Introduction}

Aluminum and its alloys are widely used in the transportation, aircraft, and marine industry where lightweight, corrosion resistance and high fatigue strength are the desired properties. In 5000 series aluminum alloys, the chief alloying element is magnesium (Howard et al 1969), one of the most effective and widely used additives for aluminum. Magnesium up to approximately $5 \%$, as an alloying element in aluminum gives a strong highly weldable alloy. Manganese may be used with magnesium to increase alloy strength. The alloys in this series have good corrosion resistance, as well as high strength, which give them fine qualities for structural members.

*For correspondence 
Consequently, if a fabrication designed for fusion welding is to have the highest possible weld strength and ductility, an alloy such as 5086, 5083 and 5456 is the best selection. Out of the three aluminum alloys mentioned here, alloy 5083 is extensively used in shipbuilding. The alloy temper conditions used in the construction of ship hulls are H112, H116, and H321.

The TIG welding process has particular advantages including superior quality weld, high accuracy and low equipment cost as well as free deposits without pre-heat. The preferred welding process for aluminum alloy is TIG welding due to its comparatively easier applicability and better economy.

LB welding is characterized by its high energy density and flexibility and has obvious advantages such as high speed, low distortion and ease of automation. However, the difficulties of laser beam welding of aluminum alloys lie in their high reflectivity, porosity formation and vapourization of magnesium in the weld metal (Roesslar 1986; Moon \& Metzbower 1983; Cieslak \& Fuerschbach 1988; Katayama \& Lundin 1991; Simidzu et al 1992; Jones et al 1992). Although the causes of the problems arising in laser beam welding of aluminum alloys have been investigated, these problems have not been fully solved.

LB welding of 5083-O has attracted much attention, because of its widespread use in welded constructions. Sections $6 \mathrm{~mm}$ in thickness have been welded autogenously at $6.5 \mathrm{~m} / \mathrm{min}$ using a power of $10 \mathrm{~kW}$, which compares favourably with the parameters used for $\mathrm{CO}_{2}$ laser beam welding of steel. Weld tensile strength values equal to the base material value of $270 \mathrm{MPa}$ have been obtained (Long \& Bergmann 1992). Tensile specimens cut from autogenous butt welded $5 x x x$ series alloys failed in the fusion zone. The tensile strengths of the welds were about $90 \%$ of those in the base metals (Martukanitz \& Altshuller 1996; Hilton 1995; Ancona et al 2005, 2007; El-Batahgy \& Katsuna 2009).

In this study, a study of the mechanical properties of laser beam welding bead-on-plate welds of $5 \mathrm{~mm}$ thickness was carried out. For comparison, TIG bead-on-plate welds of the same alloys were also performed and tested. Tensile tests and micro-hardness measurements of welded joints and base metal were performed in order to determine the influence of each welding process on the mechanical properties.

\section{Experimental procedure}

In the present work, LB welding was applied to $5 \mathrm{~mm}$ thick plates of non-heat treatable aluminum alloy AA 5083-H321 using 3.5- $\mathrm{kW} \mathrm{CO} 2$ laser. Bead-on-plate welds with full penetration were performed. Plates were cut into strips of size $300 \times 150 \mathrm{~mm}$. The surfaces of the plates were cleaned using wire brush and acetone. The laser beam was focused on the surface of the weld plate.

Bead-on-plate welds were made on the aluminum alloy plates autogenously using alternating current TIG Welding with a standard 2\% thoriated tungsten electrode. Welding current and welding potential have been chosen in such a way that the heat input results through thickness melting of the plate. The welding parameters of TIG and LB welding are listed in table 1.

After welding, samples were taken across the weld for metallographic analysis and tensile tests using an EDM cutting machine. The configuration and size of the transverse tensile specimens were prepared with reference to ASTM-E8 standard. In each condition, three specimens have been tested at room temperature.

Prior to the tensile tests, the Vickers hardness profiles across the weld, heat affected zone (HAZ) and partial base metal were measured under the load of $1 \mathrm{~kg}_{\mathrm{f}}$ for $15 \mathrm{~s}$ along the centerlines of the cross-section of the tensile specimens using an automatic micro-hardness tester. 
Table 1. Welding conditions and process parameters.

\begin{tabular}{lcc}
\hline Process & TIG welding & LB welding \\
\hline Welding machine & Miller syncrowave & Rofin slab $\mathrm{CO}_{2}$ laser \\
Tungsten electrode & 2 & - \\
diameter $(\mathrm{mm})$ & & - \\
Voltage (v) & 16 & - \\
Current $(\mathrm{A})$ & 180 & 3500 \\
Welding speed (mm/min) & 150 & Helium \\
Shilding gas & Argon & 20 \\
Gas flow rate $(\mathrm{L} / \mathrm{min})$ & 40 & 3 \\
Power $(\mathrm{kW})$ & - & \\
\hline
\end{tabular}

The chemical compositions of the base metal, TIG and LB weld bead samples were measured using Vacuum Optical Emission Spark Spectrometer. The chemical compositions were found out as an average of reading taken at two locations on the weld bead.

\section{Results}

\subsection{Bead appearance}

The bead appearances of TIG and LB welded plates were shown in figures 1 and 2.

\subsection{Tensile properties}

The tensile properties of the LB weldments are compared with those of base plates and of TIG welds in figure 3. In general, the tensile properties of both TIG and LB welds were inferior to the base metal properties. All of the TIG and LB welded tensile test specimens failed in the fusion zone and not in the base metal.

The transverse tensile properties such as yield stress, ultimate tensile strength and percentage elongation of AA5083-H321 aluminum alloy joints have been evaluated. The average values of the tensile tests were presented in figure 3 . The yield and tensile strength of base metal are $262 \mathrm{MPa}$ and $291 \mathrm{MPa}$, respectively. But the yield and tensile strength of TIG welded joints are $176 \mathrm{MPa}$ and $266 \mathrm{MPa}$, respectively. This indicates that there is a $33 \%$ reduction in yield

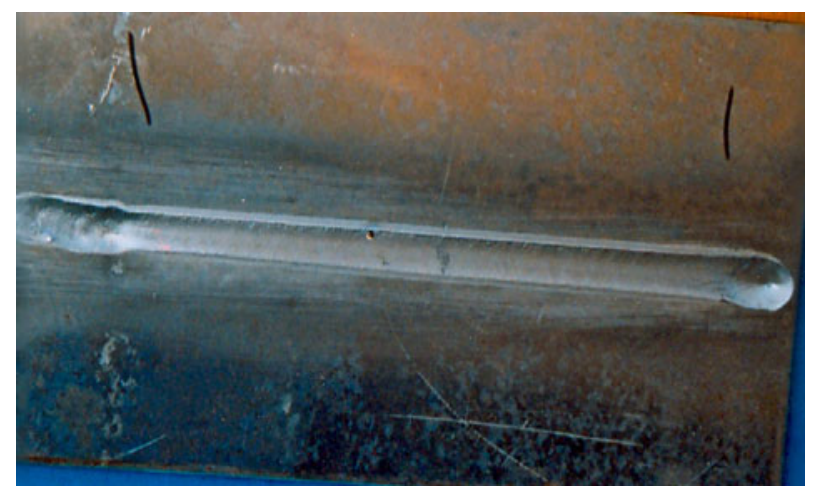

Figure 1. Bead appearance of TIG welding. 


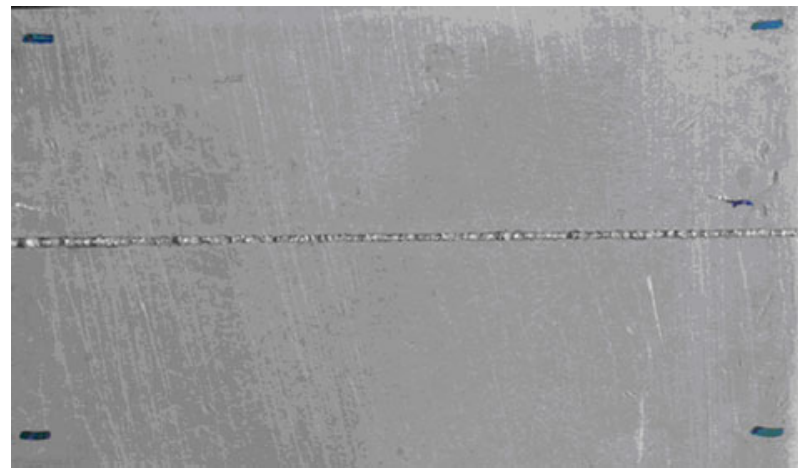

Figure 2. Bead appearance of LB welding.

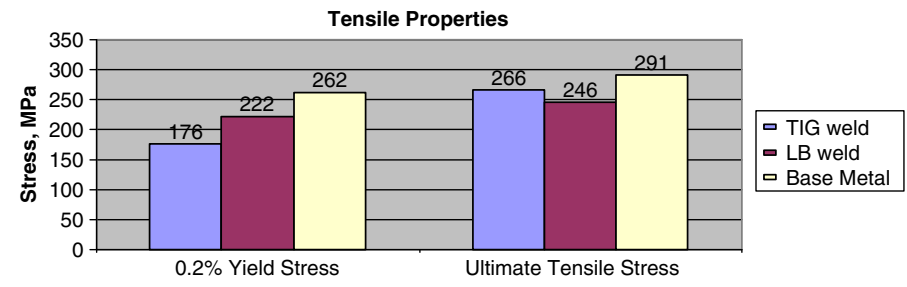

Figure 3. Tensile properties of TIG welding and Laser beam welding.

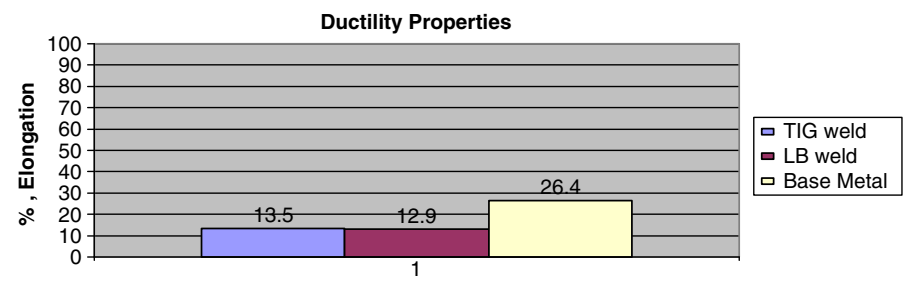

Figure 4. Ductility chart for TIG welding and LB welding.

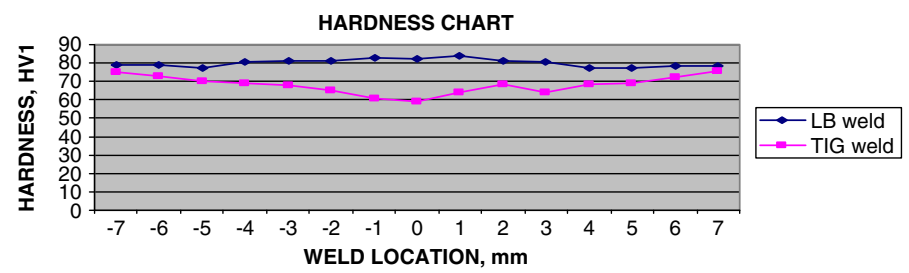

Figure 5. Hardness chart for TIG welding and LB welding. 
Table 2. Chemical composition of base metal and welded samples.

\begin{tabular}{lccccccccc}
\hline & $\mathrm{Mg} \%$ & $\mathrm{Mn} \%$ & $\mathrm{Fe} \%$ & $\mathrm{Si} \%$ & $\mathrm{Zn} \%$ & $\mathrm{Cu} \%$ & $\mathrm{Cr} \%$ & $\mathrm{Ti} \%$ & $\mathrm{Al} \%$ \\
\hline Base metal & 4.214 & 0.787 & 0.407 & 0.16 & 0.12 & 0.025 & 0.01 & 0.01 & Rest \\
TIG welding & 2.57 & 0.657 & 0.33 & 0.20 & 0.098 & 0.048 & 0.009 & 0.01 & Rest \\
LB welding & 4.790 & 0.643 & 0.373 & 0.164 & 0.01 & 0.010 & 0.024 & 0.005 & Rest \\
\hline
\end{tabular}

Table 3. Percentage gain/loss of volatile elements.

\begin{tabular}{lccc}
\hline & $\mathrm{Mg} \%$ & $\mathrm{Mn} \%$ & $\mathrm{Zn} \%$ \\
\hline Loss in TIG welding & -39 & -16.5 & -18.3 \\
Loss in LB welding & +14 & -18.3 & -91.7 \\
\hline
\end{tabular}

strength and 9\% reduction in tensile strength for TIG welding. The yield and tensile strength of LB welded samples are $222 \mathrm{MPa}$ and $246 \mathrm{MPa}$, respectively. This shows that there is a $15 \%$ reduction in both yield strength and tensile strength due to LB welding. The weld yield strength of LB welds is better than the weld yield strength of TIG welded samples by $26 \%$.

The ductility is a measure of either the percentage elongation in length or the percentage reduction in area. The percentage of elongation of the TIG and LB welds is also less than that of the base metal. The ductility of both TIG and LB welds are around 50\% of that of the base metal (figure 4).

\subsection{Hardness}

Figure 5 shows a hardness traverse from one side of the base metal, across the fusion zone, to the other side of the base metal. The reduction in strength of the TIG weldments is well-reflected in the hardness behaviour. In contrast, the reduction in strength of the LB weldments is not wellreflected in the hardness behaviour. There is a reduction of $22 \%$ hardness at the weld zone in the case of TIG welding, whereas there is an increase of $9 \%$ hardness observed at the weld zone in the case of LB welding. There is a hardness variation of $23 \mathrm{HV} 1$ in between the fusion zones of TIG and LB welding.

\subsection{Vapourization}

The chemical composition is given in table 2 for base metal as well as TIG and LB welded samples. The percentage gain/loss of the three important volatile elements was listed out in table 3. The results show that the loss of $39 \%$ magnesium, $16.5 \%$ of manganese and $18.3 \%$ zinc in the fusion zone of the TIG welded samples, whereas the percentage of magnesium present in the LB welded samples were higher than that of the base metal by $14 \%$ (gain). The manganese loss in LB welding was around $18.3 \%$. Similarly the loss of zinc in LB welded samples was very high and of the order of $91.7 \%$.

\section{Discussions}

\subsection{Bead appearance}

The weld bead appearance of LB welded plate is better than the appearance of TIG welded plate. The width of the resolidified portion of the TIG welded plate measures nearly $8 \mathrm{~mm}$, whereas 
that of the LB welded plate measures only $2 \mathrm{~mm}$. The wider width of the TIG welded plate is responsible for more evaporation of alloying elements from the weld pool, which in turn reduces its tensile properties.

\subsection{Tensile properties}

The reduction in yield strength of TIG welding by $33 \%$ is due to vapourization of magnesium, manganese and zinc from weld fusion zone, loss of strain hardening effect due to fusion welding, and the presence of pores due to formation of hydrogen porosity, etc. Whereas, there is less reduction in yield strength in LB welding, i.e., only $15 \%$ due to minimal evaporation of $\mathrm{Mg}$ elements from the weld fusion zone, minimum loss of strain hardening effect due to very less width of fusion zone and heat affected zone and consequently less porosity in the weld zone.

During LB welding process, the grain growth is controlled due to very fast heating and cooling and also due to LB welding speed of $3.5 \mathrm{~m} / \mathrm{min}$, whereas TIG welding is a slow heating and cooling process and also occurs at a slow speed of $150 \mathrm{~mm} / \mathrm{min}$, the grain growth is coarser compared to LB welding process.

\subsection{Hardness}

In our study, a higher hardness value in the fusion zone of LB welding was observed. This may be due to grain refinement effect of LB welding process. This behaviour of increasing hardness in the LB welded fusion zone was observed which also was indicated by many researchers (Cieslak \& Fuerschbach 1988; Katayama \& Lundin 1991; Punkari et al 2003).

\subsection{Vapourization}

The $39 \%$ loss of magnesium in the TIG welded samples is the main cause for the drop in yield stress value during TIG welding process. On the contrary, a slight increase of magnesium percentage in LB welds is responsible for the increase in yield stress in LB welding. Al-Mg alloys are solid-solution strengthened alloys. The reduction in the percentage of magnesium naturally affects the tensile properties of the welded joint. The loss due to evaporation of manganese also affects the tensile properties of both welded samples. It has been observed that the evaporative loss of zinc is more in the LB welded samples, because of the formation of the keyhole.

\section{Conclusions}

Laser beam welds and its effect of variation in mechanical properties and vapourization of volatile elements was compared with that of TIG welds to reveal an advantage of laser beam welding over TIG welding. The following conclusions are drawn from the above study.

(i) The LB welds shown higher yield strength than TIG welds by $26 \%$. The UTS value of LB welding was inferior to the UTS value of TIG welding by $7.5 \%$. The percentage of elongation of both TIG and LB welds are nearly the same.

(ii) Hardness survey indicates that the absolute minimum of the hardness profile is located in the fusion zone in the case of TIG welding and the absolute minimum of the hardness values are located at the Base metal in the case of LB welding.

(iii) Vapourization of volatile elements such as magnesium is more in TIG welding than in LB welding, whereas the vapourization of manganese and zinc is more in LB welding. 
Summarizing the experimental results, it can be seen that LB welding processes are more suitable for welding AA 5083-H321 when compared to TIG welding.

\section{References}

Ancona A, Sibillano T, Tricarico L, Spina R, Lugara P M, Basile G and Schiavone S 2005 Comparison of two different nozzles for laser beam welding of AA5083 aluminum alloy. J. Mater. Process. Technol. 164-165: 971-977.

Ancona A, Lugara P M, Sorgente D and Tricarico L 2007 Mechanical characterization of $\mathrm{CO}_{2}$ laser beam butt welds of AA5083, J. Mater. Process. Technol. 191: 381-384.

Cieslak M J and Fuerschbach P W 1988 Metallurgical Transactions B 19B: 319.

El-Batahgy A and Katsuna M 2009. Laser Beam Welding of AA5052, AA5083, and AA6061 Aluminum Alloys, Advances Mater. Sci. Eng., 1-9.

Hilton P A 1995 Opt. Quantum Electronics, 27: 1127-1147.

Howard E Adkins and Robert A Ridout 1969 Welding Engineer 84.

Jones I, Riches S, Yoon J W and Wallach E R 1992 Proc. LAMP '92, Nagoya, Osaka, High Temperature Society of Japan, p. 523.

Katayama S and Lundin C D 1991 J. Light Met. Weld. Constr. 29: 295.

Long A and Bergmann H W 1992 Proc. Conf. ECLAT '92, B L Mordike (ed), 163-168, Oberursel, DGMInformationsgesellchaft.

Martukanitz R P and Altshuller B 1996 Proc. ICALEO' 96: 'lasers and electro-optics for automotive manufacturing', Vol. 82, 39, Orlando; FL: Laser Institute of America.

Moon D W and Metzbower E A 1983 Welding J. 62: 53s.

Punkari A, Weckman D C and Kerr H W 2003 Sci. Technol. Weld. Join. 8: 269.

Roesslar D M 1986 The industrial laser annual handbook, Tulsa, Penn Well Books, 16.

Simidzu H, Yoshino F, Katayama S and Matsunawa A 1992 Proc. LAMP '92, Nagoya, Osaka, High Temperature Society of Japan, p. 511. 